\title{
Finansal Esneklik, Firma Değeri ve Finansal Performans ilişkisi: İnşaat Sektörü Üzerine Panel Kantil Regresyon Yaklaşımı
}

Emre Esat TOPALOĞLU (https://orcid.org/0000-0001-8771-779X), Department of Business Administration, Şirnak University, Turkey; e-mail: emresatopal@sirnak.edu.tr

Ilhan EGE (https://orcid.org/0000-0002-5765-1926), Department of Business Administration, Mersin University, Turkey; e-mail: ilhanege@mersin.edu.tr

\section{The Relationship between Financial Flexibility, Firm Value and Financial Performance: Panel Quantile Regression Approach on the Construction Sector}

\begin{abstract}
The study aimed at determining the relationship between financial flexibility, firm value, and financial performance of firms operating in the construction sector for the period 2013:12-2020:06 by employing the panel quantile regression method. Two different panel quantile regression models representing firm value and financial performance for $0.25,0.50$ and 0.75 quantile segments were created in the study. Model evaluations were performed for the Q2 $=0.5$ segment, where the absolute deviation of errors is the smallest. The results suggest that firm value and financial performance both display a significant and positive relationship with financial flexibility. It was concluded that financial flexibility is valid for companies in the construction industry.
\end{abstract}

Keywords

Financial Flexibility, Firm Value, Financial Performance, Panel Quantile Regression Approach.

JEL Classification Codes : C33, G32, L25.

\section{$\ddot{\mathbf{O} z}$}

Bu çalışmada, 2013:12-2020:06 dönemi için inşaat sektöründe faaliyet gösteren firmaların finansal esneklikleri ile firma değeri ve finansal performansları arasındaki ilişkiyi panel kantil regresyon yöntemi ile ortaya çıkarmak amaçlanmıştır. Çalışmada, $0,25,0,50$ ve 0,75 kantil dilimleri için firma değerini ve finansal performansı temsil eden iki farklı panel kantil regresyon modeli oluşturulmuştur. Hataların mutlak sapmasının en küçük olduğu Q2=0,5 dilimi için model değerlendirmeleri gerçekleştirilmiştir. Çalışma sonucunda, finansal esneklik ile firma değeri ve finansal performans arasında anlamlı ve pozitif ilişki tespit edilirken, inşaat sektöründeki firmalar için finansal esnekliğin geçerli olduğu sonucuna varılmıştır.

Anahtar Sözcükler $\quad$ : Finansal Esneklik, Firma Değeri, Finansal Performans, Panel Kantil Regresyon Yaklaşımı. 
Topaloğlu, E.E. \& İ. Ege (2021), "Finansal Esneklik, Firma Değeri ve Finansal Performans İlişkisi: İnşaat Sektörü Üzerine Panel Kantil Regresyon Yaklaşımı”, Sosyoekonomi, 29(49), 409-425.

\section{Giriş}

Finansman kararlarına ilişkin literatür incelendiğinde birçok firmanın, teorilerin aksine öngörülenden daha az borçlandığı gözlemlenmektedir. Yapılan araştırmalar firmaların sermaye yapısı kararlarının itici gücünün finansal esnekliği elde etme ve koruma arzusu olduğunu göstermektedir. Finansal esneklik, bir firmanın, fonlara düşük bir maliyetle erişme ve yeniden yapılandırma yeteneğini temsil etmektedir. Finansal esneklik, bir firmanın gelecekteki belirsiz beklenmedik durumlara zamanında yanıt olarak önleyici ve çıkarlara hizmet edici eylemler gerçekleştirmek için finansal kaynaklarını seferber etme kapasitesi olarak da tanımlanabilmektedir. Sermaye piyasalarının mükemmel olduğu durumlarda finansal esnekliğe gerek kalmamaktadır. Ancak piyasa aksaklıkları firmaların sermaye piyasalarına olan erişimini kısıtladığında, firmalar kararlarını yalnızca belirli bir koşul ve duruma yanıt olarak değil, aynı zamanda gelecekteki belirsiz durumlarla da başa çıkma girişimini de göz önünde bulundurmaktadır. Finansal olarak esnek olan firmalar, olumsuz şoklar karşısında finansal sıkıntıdan kaçabilmekte ve kârlı yatırım firsatları ortaya çıktığında yatırımları kolayca finanse edebilmektedir (Gamba \& Triatis, 2008: 2263; Byoun, 2011: 2).

Firmalarda mevcut birikmiş fonlar düşük, mevcut borç seviyesi yüksek ve gelecekteki nakit akışı düşük ise firmaların gelecekte fon sıkıntısı yaşama olasılıkları artmaktadır. Yöneticilerin ödeme kararları alırken öngörülerini kullandığı varsayımı altında, ödemeleri artırma kararları, firmanın mevcut durumda yüksek düzeyde finansal esnekliğe sahip olduğunu (yüksek nakit seviyeleri veya düşük borç oranları) veya yöneticilerin işletme nakit akışının daha güçlü veya daha kesin hale geldiğini algıladığını ifade etmektedir (Lie, 2005: 2179). Bu doğrultuda Lie (2005) finansal olarak esnek olan firmaları yüksek nakit seviyelerine ve/veya düşük borç oranlarına sahip olmaları ile karakterize etmektedir. Finansal esneklik üzerine yapılmış çalışmalar daha yüksek nakit seviyesi ve daha düşük borç oranlarına sahip olunarak finansal esnekliğin sağlanabileceğini göstermiştir. Literatürde finansal esneklik farklı yöntemler ile ölçülebilmektedir. Gamba ve Triantis (2008) finansal esnekliği, büyüme fırsatları, nakit tutmanın maliyetleri, dış finansman maliyeti ve sermayenin tersine çevrilebilirliği faktörleri ile ölçerken, Meier vd. (2013) ise nakit ve nakit benzerleri ve finansal kaldıraç ile finansal esnekliği belirlemeye çalışmıştır. Ayaydın vd. (2014) firmaların yüksek nakit düzeyleri ve düşük kaldıraç oranları ile finansal esneklik değerlerini tespit ederken, yine aynı yıl Rapp vd. (2014) ise finansal esnekliği büyüme firsatları, kârlılık, nakit tutmanın maliyetleri, dış finansman maliyeti ve sermayenin tersine çevrilebilirliği olmak üzere 5 faktörü esas alarak tespit etmeye çalışmıştır. Abdioğlu ve Aytekin (2016) çalışmalarında finansal esnekliği, Ayaydın vd. (2014) tarafından yapılan çalışmada olduğu gibi yüksek nakit seviyesi ve düşük kaldıraç oranının finansal esnekliğin temel belirleyicileri olduğunu ortaya koymuşlardır. Ma ve Jin (2016) ise nakit, içsel-dışsal özsermaye ve dış borç finansman yeteneği faktörlerini kullanarak finansal esneklik endeksini oluşturmuşlardır. DeAngelo vd. (2018) ve Gu ve Yuan (2020) çalışmalarında firmaların finansal olarak esnek olup olmadığını kaldıraç kullanımı ve nakit düzeyini esas alarak belirlemişlerdir. 
Finansal esnekliğe ilişkin literatüre göre firmaların kaldıraçtan düşük düzeyde yararlanmaları ve yüksek nakit mevcuduna sahip olmaları, firmalarda finansal esnekliğe yol açmakta ve bu durum da firmaların finansal performanslarına ve firma değerlerine olumlu katkı yapabilmektedir. Diğer bir deyişle, firmaların yatırım finansmanında yabancı kaynakları daha az kullanmaları ve nakit dönüşüm sürelerinin kısa olması yani yüksek düzeyde nakit varlığa sahip olarak kısa vadede finansal sıkıntı ve iflas maliyetleri ile karşı karşıya kalmamaları bu firmaların finansal olarak esnek olduğunun göstergeleri olabilmektedir.

2008 yılında yaşanan küresel finansal kriz sonrasında gerçekleşen menkulleştirme süreci konut sektöründe kırılma noktası olmuştur. Son dönemlerde Türkiye'de inşaat odaklı büyüme modelinin benimsenmesi doğrultusunda özellikle kriz sonrasında konut piyasalarının yeniden düzenlenmesi ve finansal derinliğin sağlanması gerekli hale gelmiştir. Türkiye'nin önemli sektörlerinden biri olan inşaat sektöründe faaliyet gösteren firmalar, yaptıkları her bir yeni projenin kar esaslı olmasını, alacak, stok ve yabancı kaynak finansman yönetiminin ise optimal şekilde gerçekleştirilmesini hedeflemektedir. Bu bağlamda inşaat firmaları, şantiye veya yeni projelerinde nakit yönetimini ve finansman politikalarını bir arada ve eşzamanlı şekilde oluşturmalıdır. $\mathrm{Bu}$ bağlamda inşaat firmalarının temel politikasının, bankalardan sağlanacak orta ve uzun vadeli kredilerde ve diğer fon kaynaklarında maliyeti düşürerek mevcut işletme sermayelerini ve nakit varlıklarını optimize etmek olduğu söylenebilir.

Çalışmada, inşaat sektöründe faaliyet gösteren firmaların finansal esneklikleri ile firma değerleri ve finansal performansları arasındaki ilişkiyi ortaya çıkarmak amaçlanmıştır. İnşaat sektörünün 2013-2020 dönemindeki verilerin analiz edildiği araştırmada elde edilen bulguların başta inşaat sektöründeki firmalar olmak üzere yatırımcılara ve hem sektörel hem de firma paydaşlarına yol gösterici nitelikte olması hedeflenmiştir. Bu bağlamda çalışma üç bölümden oluşmaktadır. Birinci bölüm literatür taramasında finansal esnekliğe ilişkin gerçekleştirilen çalışmalarda ulaşılan bulgulara yer verilmiştir. Çalışmanın ikinci bölümünde ise finansal esneklik ile firma değeri ve finansal performans arasındaki ilişki panel kantil regresyon yöntemi ile analiz edilmiş ve elde edilen analiz sonuçları raporlanmıştır. Son bölümde ise araştırmada ulaşılan bulgular değerlendirilip yorumlanmıştır. Finansal literatür incelendiğinde, finansal esnekliğe ilişkin çalışmaların özellikle yurtiçinde kısıtlı olduğu görülmektedir. Finansal esnekliğin firma değeri ve finansal performansa olan etkisinin birlikte incelendiği herhangi bir çalışmaya rastlanılmamış olmasının yanı sıra çalışmada inşaat sektörünün panel veri olarak ele alınması ve panel kantil regresyon analizi ile olası ilişkilerin araştırılması, çalışmanın özgün değerini ve literatüre olan katkısını ortaya koymaktadır.

\section{Literatür Taraması}

Finansal esneklik kavramına ilişkin yapılan çalışmalar incelendiğinde bu çalışmaların finansal performans, firma değeri, yatırımlar, finansman kararları ve nakit yönetimi üzerine yoğunlaştığını söylemek mümkündür. Düşük kaldıraç oranı ve yüksek 
nakit düzeyi ile ilişkilendirilen finansal esneklik ile finansal performans ve firma değeri arasındaki ilişkilerin incelendiği bazı çalışmalarda elde edilen bulgular aşağıda yer almaktadir.

Ayaydın Arslan vd. (2008) tarafından yapılan çalışmada, Doğu Asya firmalarında finansal esnekliğin kriz öncesi ve kriz sürecinde firmaların yatırım ve finansal performansı üzerindeki etkileri incelenmiştir. Kriz öncesinde finansal esnekliğe sahip olan firmaların finansal esnekliğe sahip olmayan firmalara göre yatırım yapma yeteneklerinin ve performanslarının daha iyi olduğu sonucuna ulaşılırken, aynı zamanda finansal olarak esnek firmaların kriz sürecinde de performanslarının daha yüksek olduğu sonucuna ulaşılmıştır. Gamba ve Triantis (2008) çalışmalarında, finansal esnekliğin firma değeri üzerindeki etkisini ölçebilmek için finansman, yatırım ve nakit tutma politikalarını içselleştiren bir model geliştirilmiştir. Modelde yüksek düzeyde finansal esnekliği olan firmaların daha yüksek düzeyde firma değerine sahip oldukları belirlenmiştir.

Marchica ve Mura (2010), 1965-2008 Birleşik Krallık firma verilerinden hareketle finansal esneklik ve yatırım kapasitesi arasındaki ilişkiyi inceledikleri çalışmalarında finansal esnekliğin yatırım kapasitesini önemli ölçüde etkilediği sonucuna ulaşılmıştır. Yapılan analizlerin sonucunda; finansal olarak esnek olan firmaların önemli ölçüde daha fazla yatırım yapabilecekleri, finansal esnekliğin ortalama bir firma yatırımını \%37 oranında artırabileceği tespit edilmiştir. Çalışmada firmaların finansal esnekliğinin uzun vadede firma performansında da artışa yol açtığı ve firma değerini artırdığı sonucuna da ulaşılmıştır.

Waghmare vd. (2011) Hindistan'daki 5 firma için yaptıkları çalışmalarında finansal esneklik ve firma yapısının firma performansına etkisini incelemektedir. Yapılan analizde hem finansal esnekliğin hem de firma yapısının firmanın finansal performansı üzerinde olumlu etkisi olduğu fakat firma yapısının firmanın finansal performansı finansal esneklikten daha fazla etkilediği sonucuna ulaşılmıştır.

Mokhtar vd. (2013) tarafından yapılan çalışmada ise 2006-2011 döneminde Malezya borsasında işlem gören firmaların finansal esneklikleri ile finansal performansları arasındaki ilişki araştırılmıştır. Araştırma neticesinde, yüksek nakit mevcuduna ve düşük kaldıraç oranına sahip firmaların finansal esnekliğe sahip oldukları ve bunun da finansal performansı artırdığı yönünde bulgulara ulaşılmıştır.

Liping, Zhe ve Shu (2013) çalışmalarında, Çin Borsasında işlem gören firmaların finansal esneklikleri ile yatırım ve firma performansı arasındaki ilişkiyi incelemişlerdir. Çalışmada, düşük kaldıraç ve yüksek nakit düzeyinin finansal esnekliğe yol açtığı ve finansal esnekliğin sonraki dönemlerde finansal performansı ve yatırımları artırdı̆̆ sonucuna ulaşılmıştır.

Chen ve Hsiao (2014)'nun çalışmalarında ABD'deki finansal esnek olmayan firmaların 1992-2009 dönemi için içeriden bilgi sahibi olmanın finansal esnekliğe etkisi ve nakit akışı duyarlılığı temsil maliyeti teorisi çerçevesinden incelenmektedir. Yapılan analiz 
sonucunda içeriden bilgi sahibi olmanın temsilci maliyet kanalı aracılığıyla finansal esnekliği etkilediği tespit edilmiştir. Ayrıca çalışmada yapılan analizlere göre, finansal sıkıntı ve iflas maliyetleri ile karşı karşıya olan şirketlerde içeriden bilgi sahipliğinin orta düzeyde olduğu durumda finansal esneklik yüksekken; içeriden bilgi sahibi olmanın kısıtlanmadığı şirketlerde içeriden bilgi sahibi olmanın finansal esneklik üzerindeki etkisinin minimum olduğu belirlenmiştir.

Ayaydın vd. (2014), 1994-2009 döneminde Doğu Asya firmalarında finansal esnekliğin yatırımlar ve firma performansı üzerine etkilerini inceledikleri çalışmalarında, finansal esnekliğin özellikle 1997-1998 Asya krizi döneminde yatırım ve firma performansını önemli ölçüde etkilediği sonucuna ulaşılmıştır. Bu kriz öncesinde finansal olarak esnek olan firmaların hem yatırım kapasitelerinin hem de firma performanslarının daha iyi olduğu tespit edilmiştir. Bu etkinin 2007-2009 küresel finansal krizi esnasında da esnek firmalar açısından sürdüğü ifade edilen çalışmada ayrıca finansal esneklik düzeyinin bölgelerin ya da ülkelerin makroekonomik politikalarına göre farklılaştığı da belirtilmektedir.

Choi vd. (2015)'nin çalışmasında ABD firmalarının dış kaynak kullanımı için şirkete özgü verileri ve piyasa verilerinden hareketle firma değeri aracı olarak finansal esneklikleri incelenmiştir. Çalışmada firmaların belirsiz piyasa ve çevresel koşullar altında dış kaynak esnekliğine sahip olmaları durumunda finansal performanslarının artma eğiliminde oldukları sonucuna ulaşılmıştır.

Abdioğlu ve Aytekin (2016) çalışmalarında, imalat sektöründe faaliyet gösteren firmalarda 2005-2014 dönemi için finansal esnekliğin firma performansı üzerindeki etkisini incelemişlerdir. Çalışma sonucunda, düşük kaldıraç ve yüksek nakit mevcuduna sahip firmaların finansal esnekliğe sahip oldukları ve finansal esnekliğin firma performansını pozitif yönde etkilediği tespit edilmiştir.

Aynı yıl yapılan bir diğer çalışmada ise Ma ve Jin (2016), borsaya kayıtlı Çin şirketlerinin verilerinden hareketle finansal esnekliğin firmaların yatırım performansına ve firma performansına etkisini incelemektedir. Yapılan analiz sonucunda, finansal esnekliğin hem yatırım performansı hem de firma performansı üzerinde olumlu ve önemli bir etkisi olduğu tespit edilmiştir.

Chang ve Ma (2019), Uzak Doğu ülkelerinin sermaye piyasalarına uygun olarak geliştirilmiş bir finansal esneklik endeksine sahip 287 Çin borsasına kayıtlı firmanın 20102012 dönemindeki verileri doğrultusunda finansal esnekliğin firma performansına etkisini inceledikleri çalışmalarında, finansal esnekliği olan firmaların finansal performanslarının daha yüksek olduğu sonucuna ulaşılmıştır.

Altaf (2020)'ın 185 Hindistan konaklama firması için finansal esneklik ve finansal performans ilişkisini incelediği çalışmada, finansal esnekliğin kısa vadeli borç kullanarak 
daha büyük bir işletme sermayesi oranını finanse ederek firma performansını artırdığı tespit edilmiştir.

Finansal esnekliğe ilişkin literatür doğrultusunda bu çalışmada, Türkiye'de son dönemlerde yapılan yatırımlar ve gelişmekte olan ülkelerde ekonomik büyümeye olan pozitif etkisi doğrultusunda majör sektörlerden biri haline gelen inşaat sektöründeki firmalar açısından finansal esnekliğin finansal performans ve firma değeri üzerindeki etkisinin araştırılması hedeflenmiştir. İnşaat sektörü, diğer sektörler ile geniş ve yoğun bir ilişki içerisindedir. İnşaat sektörü bir yandan diğer mal ve hizmetlerin üretilebilmesine gereksinim yaratabilmektedir. Aynı zamanda sektörün yoğun işgücüne ihtiyaç duyması diğer sektörlerde istihdam yaratabilmekte ve yatırımları artırabilmektedir. Finansal esneklik ile finansal performans ve firma değeri arasındaki ilişkinin panel kantil regresyon yöntemiyle incelenmesi açısından çalışmanın öncü çalışmalardan olduğu ve literatüre katkı sağladığı düşünülmektedir.

\section{Amaç ve Yöntem}

Çalışmanın araştırma aşamasında Borsa İstanbul (BIST) inşaat endeksinde faaliyet gösteren dokuz firmanın 2013:12-2020:06 dönemi için finansal esneklik ile firma değeri ve finansal performans arasındaki ilişkiyi panel kantil regresyon yöntemi ile ortaya çıkarmak amaçlanmıştır. Çalışmada analiz edilen veriler firmaların mali raporlarından ve Finnet veri tabanından elde edilmiş ve de Eviews 12 paket programı ile analizler gerçekleştirilmiştir. Çalışmada incelenen firmalara ilişkin temel bilgiler Tablo 1'de sunulmaktadır.

Tablo: 1

\section{Çalış̧mada İncelenen İnşaat Firmaları}

\begin{tabular}{|c|l|l|}
\hline Sıra & BIST KODU & Firma Adı \\
\hline 1 & ANELE & Anel Elektrik Proje Taahhüt ve Ticaret A.Ş. \\
\hline 2 & EDIP & Edip Gayrimenkul Yatı̈ım Sanayi ve Ticaret A.Ş. \\
\hline 3 & ENKAI & Enka İnşaat ve Sanayi A.Ş. \\
\hline 4 & KUYAS & Kuyumcukent Gayrimenkul Yatırımları A.Ş. \\
\hline 5 & ORGE & Orge Enerji Elektrik Taahhüt A.Ş. \\
\hline 6 & SANEL & San-El Mühendislik Elektrik Taahhüt Sanayi ve Ticaret A.Ş. \\
\hline 7 & TURGG & Türker Proje Gayrimenkul ve Yatırım Geliştirme A.Ş. \\
\hline 8 & YAYLA & Yayla Enerji Üretim Turizm ve İnşaat Ticaret A.Ş. \\
\hline 9 & YYAPI & Yeşil Yapı Endüstrisi A.Ş. \\
\hline
\end{tabular}

Panel kantil regresyon analizinde panel veri analizine ilişkin çoklu doğrusal bağlantı, içsellik, yatay kesit bağımlılığı ve durağanlık varsayımlarının sınanması gerekmektedir. Ek küçük kareler (EKK) yöntemi kullanılarak gerçekleştirilen tahminlemelerde varsayımların sağlanamadığı durumda etkin ve geçerli sonuçlar elde edilememektedir. Bu bağlamda EKK yöntemine alternatif yöntemlerden biri Kantil Regresyon analizidir. Kantil regresyon analizinde, EKK'nın aksine hata varyansının homojenliği ve hataların dağılımına ilişkin herhangi bir varsayım söz konusu değildir ve lineer regresyon modelinden daha esnek bir yaklaşım olarak karşımıza çıkmaktadır. Klasik regresyon modelinde tahminleme bağımlı değişkenin koşullu beklenen değeri için gerçekleştirilirken, kantil regresyon modelinde ise bağımlı değişkenin koşullu dağılımında seçilen kantiller için tahminleme 
gerçekleştirilmektedir. Kantil regresyon modelinin klasik regresyon modelinden bir diğer farkı da kantil regresyon fonksiyonlarının koşullu ortalama ile artık kareler toplam minimizasyonu yerine mutlak artıkların ağırlıklandırılmış toplam minimizasyonuna dayanmasıdır (Altın-Yavuz \& Gündoğan-Aşık, 2017; Özel \& Sezgin, 2012). Panel Kantil regresyon modelinin istatistiksel gösterimi aşağıdaki gibidir:

$$
y_{i, t}=x_{i, t} \beta_{\theta}+u_{\theta}
$$

1 numaralı eşitlikte $x$,i,t, açıklayıcı değişken vektörüdür ve $y_{i, t}$ 'nin koşullu dağılımının $\theta$ 'nci kantili ile açıklayıcı değişkenler arasındaki doğrusal regresyonu ifade etmektedir. $\beta_{\theta}, \theta$ 'nci kantil regresyonla ilgili parametre vektörünü temsil ederken, $u_{\theta i, t}$, hata vektörünü temsil etmektedir. $\mathrm{y}_{\mathrm{i}, \mathrm{t}}$ 'nin $\theta$ 'nci koşullu kantili,

$$
\mathcal{Q}\left(y_{i, t} / x_{i, t}\right)=x_{i, t} \beta_{\theta}
$$

Kantil regresyonun amaç fonksiyonu, mutlak sapmaların ağırlıklandırılmış toplamlarını ifade etmektedir. $\theta$ 'nci kantil regresyon için amaç fonksiyonu ise;

$$
\min _{\beta} \frac{1}{n}\left\{\sum_{\theta y \geq x_{i, t} \beta} \theta\left|y_{i, t}-x_{i, t} \beta\right|+\sum_{\theta y<x_{i, t} \beta}(1-\theta)\left|y_{i, t}-x_{i, t} \beta\right|\right\}
$$

şeklinde ifade edilirken aşağıdaki eşitlik ile tahminleme gerçekleştirilmektedir.

$$
\hat{\beta_{\theta}}=\frac{1}{n} \sum_{i, t=1}^{n} \rho_{\theta}\left(y_{i, t}-x_{i, t} \beta\right)=\sum_{i, t}^{n} \rho_{\theta}\left(u_{\theta_{i, t}}\right)
$$

Kantil regresyon analizi, Koenker ve Bassett (1978) tarafından yapılan çalışmalardan sonra birçok araştırmada uygulama alanı olmuştur. EKK yönteminde tüm gözlem değerlerine eşit ağırlık verirken, kantil regresyon yönteminde ise bağımlı değişkenin koşullu dağılımındaki farklı dilimler için ağırlıklandırmalar yapılmaktadır. Buna göre EKK yönteminin dikkate almadığı uç değerler için farklı modeller kurulabilmekte ve tahminleme yapılabilmektedir. Araştırmada finansal esnekliğin firma değerine ve finansal performansa olan etkisini ölçebilmek için iki farklı panel kantil regresyon modeli oluşturulmuştur. Modellerde kullanılan bağımlı değişkenler aktif kârlılık oranı (Net Kar/Toplam Aktif (ROA) ve Tobin's Q (Piyasa Değeri + Toplam Borç/Toplam Varlıklar) oranı olarak belirlenirken, açıklayıcı değişkenler olarak ise yüksek nakit (para ve benzeri değerler/toplam varlıklar (YN) ve düşük kaldıraç (toplam borçlar/toplam varlık (DK) oranı belirlenmiştir. Buna ek olarak firma büyüklüğü (Toplam Aktiflerin Logaritması (BUY), büyüme firsatı (Net Satışlar t / Net Satışlar t-1 (BUYFIR) kontrol değişkenleri olarak modele dahil edilmiştir. Modelde kontrol değişkenlerine yer verilmesinin sebebi, açıklayıcı değişken konumunda olan YN ve DK değişkenlerinin kukla değişken niteliğinde olması ve modellerin açıklama gücünün artırılma gerekliliğidir. Buna ek olarak ROA esas alınarak oluşturulan modele Tobin's Q oranı piyasa göstergesi açıklayıcı değişkeni olarak modele dahil edilirken, Tobin's Q oranı esas alınarak oluşturulan modele de ROA açıklayıcı değişken olarak dahil edilmiştir. 
Finansal esneklik göstergeleri olan yüksek nakit ve düşük kaldıraç değişkenleri için dummy (kukla) değişkenler oluşturulmuştur. Buna göre eğer bir firmanın kaldıraç değeri, örneklemin kaldıraç değerinin medyanından küçük ise bu değişken 1 değerini alırken, büyük ise 0 değerini almaktadır. Yüksek nakit değişkeninde ise bir firmanın nakit mevcudunun toplam aktiflere oranı örneklemin medyanından büyükse 1, küçükse 0 değerini almakta ve böylelikle kukla değişkenler oluşturulmaktadır (Abdioğlu \& Aytekin, 2016). Çalışmanın finansal esneklik değişkenlerinin kukla değişkenler olması ve firma değeri ve finansal performans üzerindeki uç değerler dikkate alınarak tahminleme yapılacak olması doğrultusunda araştırmada yöntem olarak panel kantil regresyon analizinin tercih edilmiştir.

$$
\begin{aligned}
& R O A_{i t}\left(\tau \backslash X_{i t}\right)=\beta_{1}(\tau) Y N_{i, t}+\beta_{2}(\tau) D K_{i, t}+\beta_{3}(\tau) T O B I N Q_{i, t}+\beta_{4}(\tau) B U Y_{i, t}+ \\
& \beta_{5}(\tau) B U Y F I R_{i, t}+\alpha_{\mathrm{i}}+U_{i, t} \\
& T O B I N Q_{i t}\left(\tau \backslash X_{i t}\right)=\beta_{1}(\tau) Y N_{i, t}+\beta_{2}(\tau) D K_{i, t}+\beta_{3}(\tau) R O A_{i, t}+\beta_{4}(\tau) B U Y_{i, t}+ \\
& \beta_{5}(\tau) B U Y F I R_{i, t}+\alpha_{\mathrm{i}}+U_{i, t}
\end{aligned}
$$

Finansal performans ve firma değeri için oluşturulan kantil regresyon modellerinde $\tau$ kantil değerini, Xit, açıklayıcı değişkeni, $\alpha$ i sabit etkiyi ve $u_{i t}$ ise hata terimini ifade etmektedir.

Oluşturulan modeller doğrultusunda çalışmada iki temel hipotez sınanmıştır. Düşük kaldıraç oranı ve yüksek nakit mevcudu ile ROA ve TOBIN's Q bağımlı değişkenleri arasında anlamlı ve pozitif yönlü ilişkinin tespit edilmesi firmaların finansal esnekliğe sahip olmaları anlamına gelmektedir. Bu bağlamda sınanan iki temel hipotez; " $\mathrm{H}_{1}$ : Finansal esneklik ile finansal performans arasında pozitif ilişki vardır" ve " $\mathrm{H}_{2}$ : Finansal esneklik ile firma değeri arasında pozitif ilişki vardır” şeklindedir.

\section{Bulgular}

Panel kantil regresyon analizinde ulaşılan bulgulara geçmeden önce oluşturulan modellerde çoklu doğrusal bağlantı ve içsellik sorunlarının olup olmadığı incelenmiştir. Açıklayııı değişkenler arasındaki yüksek düzeyli ilişki çoklu doğrusal bağlantıya sebep olurken, bağımlı değişken ile açıklayıcı değişkenler arasındaki yüksek düzeyli ilişki ise içsellik sorununa yol açmaktadır. Çoklu doğrusallık ve içsellik sorunları ile tahminleme yapıldığı takdirde elde edilen analiz sonuçları ve özellikle modelin açıklama gücünde tutarsız ve sahte sonuçlar elde edilebilmektedir. Modellerde çoklu doğrusallık ve içsellik, normal dağılım varsayımının geçerli olmadığı koşulda kullanılan Spearman korelasyon testi ile incelenmiştir. 
Tablo: 2

Spearman Korelasyon Testi Sonuçları

\begin{tabular}{|c|c|c|c|c|c|c|c|c|c|}
\hline Korelasyon & & & & & & & & & \\
\hline \multicolumn{10}{|l|}{ t-İstatistik } \\
\hline Olasılık & ROA & ROE & TOBIN & YN & DK & DURVY & BUYFIRS & BUY & BORCVY \\
\hline \multirow[t]{3}{*}{ ROA } & 1,0000 & & & & & & & & \\
\hline & ----- & & & & & & & & \\
\hline & - --- & & & & & & & & \\
\hline \multirow[t]{3}{*}{ ROE } & 0,9922 & 1,0000 & & & & & & & \\
\hline & 88,644 & ----- & & & & & & & \\
\hline & 0,0000 & ----- & & & & & & & \\
\hline \multirow[t]{3}{*}{ TOBIN } & 0,2259 & 0,1871 & 1,0000 & & & & & & \\
\hline & 2,5823 & 2,1208 & ---- & & & & & & \\
\hline & 0,0110 & 0,0359 & ----- & & & & & & \\
\hline \multirow[t]{3}{*}{ YN } & 0,3143 & 0,2734 & 0,3629 & 1,0000 & & & & & \\
\hline & 3,6867 & 3,1655 & 4,3364 & ----- & & & & & \\
\hline & 0,0003 & 0,0019 & 0,0000 & ----- & & & & & \\
\hline \multirow[t]{3}{*}{ DK } & 0,3246 & 0,2510 & 0,4214 & 0,3651 & 1,0000 & & & & \\
\hline & 3,8218 & 2,8873 & 5,1737 & 4,3668 & ----- & & & & \\
\hline & 0,0002 & 0,0046 & 0,0000 & 0,0000 & ----- & & & & \\
\hline \multirow[t]{3}{*}{ DURVY } & $-0,3335$ & $-0,3486$ & $-0,1584$ & $-0,3742$ & 0,0513 & 1,0000 & & & \\
\hline & $-3,9387$ & $-4,1413$ & $-1,7859$ & $-4,4937$ & 0,5718 & ----- & & & \\
\hline & 0,0001 & 0,0001 & 0,0766 & 0,0000 & 0,5685 & ---- & & & \\
\hline \multirow[t]{3}{*}{ BUYFIRS } & 0,2819 & 0,2947 & 0,0581 & 0,0203 & $-0,0351$ & $-0,0536$ & 1,0000 & & \\
\hline & 3,2712 & 3,4347 & 0,6477 & 0,2260 & $-0,3914$ & $-0,5980$ & ----- & & \\
\hline & 0,0014 & 0,0008 & 0,5184 & 0,8216 & 0,6961 & 0,5509 & ----- & & \\
\hline \multirow[t]{3}{*}{ BUY } & 0,1345 & 0,1437 & $-0,4501$ & $-0,0408$ & $-0,1342$ & 0,1472 & $-0,0947$ & 1,0000 & \\
\hline & 1,5109 & 1,6173 & $-5,6129$ & $-0,4548$ & $-1,5080$ & 1,6568 & $-1,0593$ & ----- & \\
\hline & 0,1334 & 0,1084 & 0,0000 & 0,6501 & 0,1341 & 0,1001 & 0,2915 & ----- & \\
\hline \multirow[t]{3}{*}{ BORCVY } & 0,2025 & 0,2212 & $-0,0924$ & 0,0901 & $-0,0762$ & $-0,8382$ & 0,0103 & 0,0007 & 1,0000 \\
\hline & 2,3023 & 2,5259 & $-1,0332$ & 1,0076 & $-0,8505$ & $-17,114$ & 0,1144 & 0,0076 & $-\cdots$ \\
\hline & 0,0230 & 0,0128 & 0,3035 & 0,3156 & 0,3967 & 0,0000 & 0,9091 & 0,9940 & - ---- \\
\hline
\end{tabular}

Korelasyon tablosunda değişkenler arasındaki ilişki düzeylerini gösteren korelasyon katsayıları, t-istatistik değerleri ve olasılık değerleri gösterilmektedir. Çoklu doğrusal bağlantı ve içsellik durumlarının tespiti için değişkenler arasındaki korelasyon ilişkisinin anlamlı olması değil burada önemli olan korelasyon katsayı değerleridir. Korelasyon testi sonuçlarına göre model spesifikasyonu için belirlenen değişkenler arasında özsermaye kârlılığı (ROE), duran varlık yapısı (DURVY) ve borcun vade yapısı (BORCVY) değişkenleri tespit edilen yüksek düzeyli iliş̧kilerden dolayı modellere dâhil edilmemiştir. Modelde bağımlı değişken konumunda olan ROA ile bağımsız değişken olarak modele dâhil edilmek istenilen ROE arasındaki yüksek düzeyli ilişki içsellik sorununa yol açmaktadır. Dolayısıyla ROE herhangi bir modele bağımsız değişken olarak eklenememiştir. Diğer taraftan DURVY ve BORCVY değişkenlerini aynı modele dâhil etmek çoklu doğrusal bağlantı sorununa yol açmaktadır. Bu doğrultuda sonuçlarda sapmaya ve tutarsızlığa yol açmaması adına değişkenler arasında herhangi bir seçim yapılmamış ve her iki değişken de modele dâhil edilmemiştir. Bu bağlamda modellerdeki doğrusallık ve içsellik sorunları ortadan kaldırılarak diğer değişkenler ile modeller kurgulanmıştır. Tablo 3 ve Şekil 1'de modellerde kullanılan değişkenlerin tanımlayıcı istatistikleri ve dağılım grafikleri yer almaktadır. 
Tablo: 3

Tanımlayıcı İstatistikler

\begin{tabular}{|c|c|c|c|c|c|c|}
\hline & ROA & TOBIN'S Q & YN & DK & BUYFIR & BUY \\
\hline Ortalama & 0,0338 & 1,1289 & 0,5000 & 0,5000 & 1,3202 & 19,7622 \\
\hline Medyan & 0,0022 & 1,0251 & 0,5000 & 0,5000 & 1,0851 & 19,2671 \\
\hline Maksimum & 0,4375 & 2,3538 & 1,0000 & 1,0000 & 4,5026 & 24,7442 \\
\hline Minimum & 0,0000 & 0,4717 & 0,0000 & 0,0000 & 0,0110 & 17,3433 \\
\hline Std. Sap. & 0,0620 & 0,3894 & 0,5020 & 0,5020 & 0,9234 & 1,8392 \\
\hline Çarpıklık & 3,4214 & 0,9632 & 0,0000 & 0,0000 & 0,5171 & 1,1775 \\
\hline Basıklık & 18,539 & 3,3445 & 1,0000 & 1,0000 & 2,5016 & 3,9480 \\
\hline Jarque-Bera & 1513,5 & 20,107 & 21,000 & 21,000 & 6,9195 & 33,836 \\
\hline Olasılık & 0,0000 & 0,0000 & 0,0000 & 0,0000 & 0,0314 & 0,0000 \\
\hline Gözlem Sayıs1 & 126 & 126 & 126 & 126 & 126 & 126 \\
\hline
\end{tabular}

Tanımlayıcı istatistik sonuçlarına göre, ROA ve TOBINQ oranlarının ortalama değerlerine göre inşaat sektöründeki firmaların kârlı oldukları ve piyasa değerlerinin de yüksek olduğu söylenebilir. BUYFIR ve BUY değişkenlerinin ortalama değerlerine göre de firmaların büyüklüklerinin yükseliş potansiyelinde olduğunu ifade etmek mümkündür. Çarpıklık, basıklık ve J-B değerleri incelendiğinde değişkenlerin normal dağılmadıkları belirlenmiştir.

\section{Şekil: 1}

Model ve Değişskenlerin Dağılım Grafikleri

Model (ROA ve TOBIN'S Q)
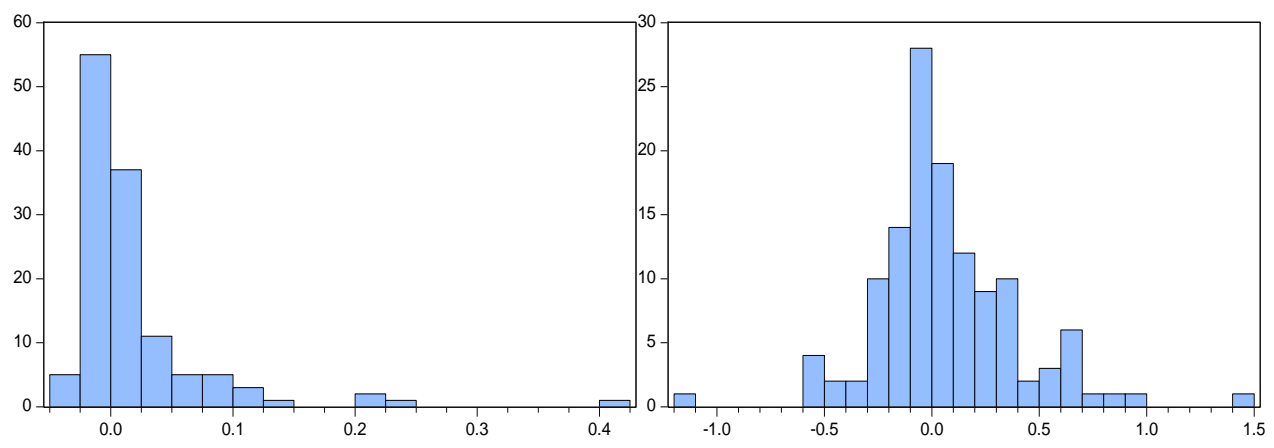
ROA ve TOBIN'S $Q$
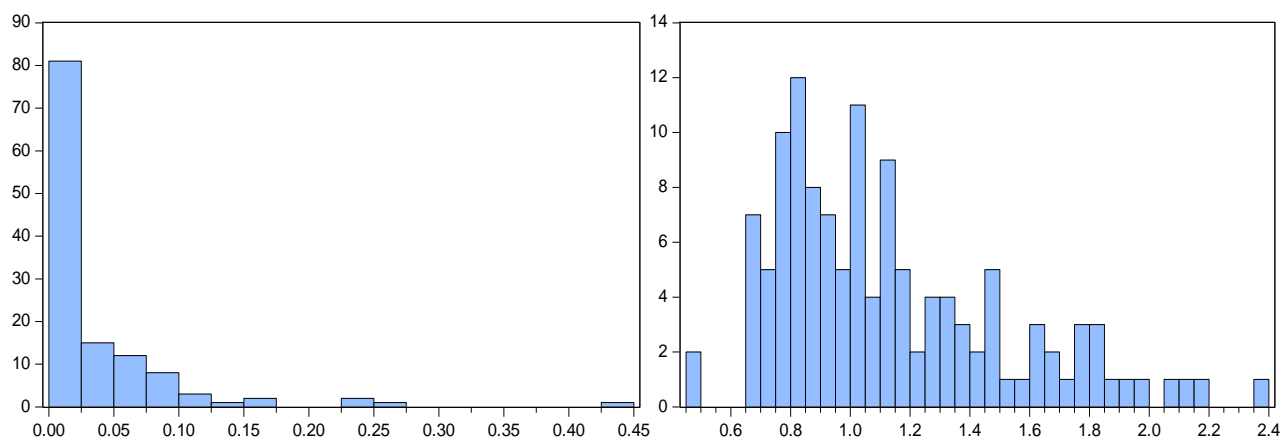

BUYFIRS ve BUY

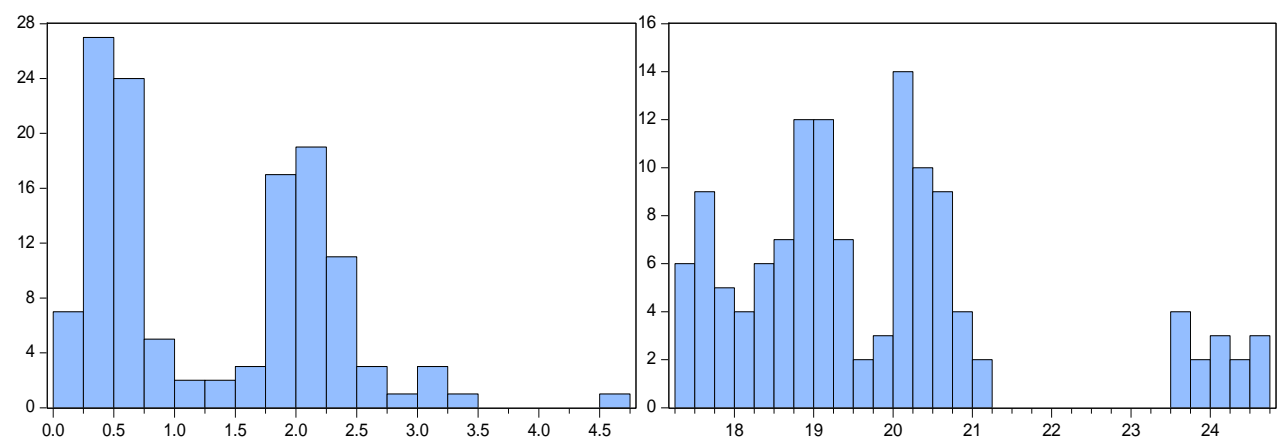

Şekil 1'de olduğu üzere dağılım grafikleri kukla değişkenler dışındaki diğer tüm değişkenler ve modeller esas alınarak oluşturulmuştur. Normal dağılım grafikleri incelendiğinde hem model bazında hem de değişkenler bazında serilerin normal dağılmadıkları söylenebilir. Finansal ve iktisadi değişkenlerde volatilite diğer bir deyişle ortalamadan sapmalar yüksek düzeyde olabilmektedir. Dolayısıyla, bu değişkenlere ilişkin serilerin normal dağılıma uymaları beklenmemektedir. Bu bağlamda finansal serilerin finansal ekonometrik analizlerde ve özellikle de panel veri analizlerinde bir sorun yaratmayacağı söylenebilir.

Panel kantil regresyon analizinde temel varsayımlardan bir diğeri de yatay kesit bağımlılı̆̆ıdır. Panel veriyi oluşturan sektörde faaliyet gösteren firmaların birinde meydana gelen bir şok diğer firmaları da etkiliyorsa yatay kesit bağımlılığı söz konusudur. Yatay kesit bağımlılı̆̆ını dikkate almadan yapılacak analizlerde elde edilen bulguların sahte ilişkiler içerebilmektedir. Çalışmanın zaman boyutunun yatay kesit boyutundan büyük olmasından dolayı değişkenlerin yatay kesit bağımlılığı Breusch-Pagan LM ve Pesaran CDlm testleri ile araştırılmıştır. Analiz sonuçları, Tablo 4'te gösterilmektedir. 
Tablo: 4

Yatay Kesit Bağımlılığı Test İstatistikleri

\begin{tabular}{|c|c|c|c|c|}
\hline \multirow{2}{*}{ Değișken } & \multicolumn{2}{|c|}{ Breusch-Pagan LM } & \multicolumn{2}{|c|}{ Pesaran CDlm } \\
\hline & İstatistik & Olasılık Değeri & İstatistik & Olasılık Değeri \\
\hline ROA & 64,543 & 0,002 & 3,364 & 0,000 \\
\hline YN & - & - & - & - \\
\hline DK & - & - & - & - \\
\hline BUYFIR & 61,582 & 0,005 & 3,015 & 0,001 \\
\hline BUY & 88,759 & 0,000 & 6,218 & 0,000 \\
\hline TOBIN & 61,996 & 0,005 & 3,064 & 0,001 \\
\hline
\end{tabular}

Breusch-Pagan LM ve Pesaran CDlm test istatistikler incelendiğinde, tüm değişkenlerde yatay kesit bağımlılığının olduğu sonucuna ulaşılmıştır. Bu durumda güvenilir sonuçlar elde edebilmek için ikinci nesil panel birim kök testlerinin kullanılması gerekmektedir. Bu doğrultuda çalışmada değişkenlerin durağanlığı Bai ve Ng (2004) PANIC ikinci nesil birim kök testi ile analiz edilmiştir.

Tablo: 5

PANIC Panel Birim Kök Testi Sonuçları

\begin{tabular}{|c|c|c|c|c|}
\hline & \multicolumn{2}{|c|}{ Sabit } & \multicolumn{2}{|c|}{ Sabit ve Trend } \\
\hline Seviye & İstatistik & Olasılık Değeri & İstatistik & Olasılık Değeri \\
\hline \multicolumn{5}{|l|}{ ROA } \\
\hline$Z_{\hat{e}}^{c}$ & 3,3271 & $0,0004 * * *$ & 2,0190 & $0,0217 * *$ \\
\hline$P_{\hat{e}}^{c}$ & 37,9625 & $0,0039 * * *$ & 30,1139 & $0,0364^{* *}$ \\
\hline \multicolumn{5}{|l|}{ TOBIN } \\
\hline$Z_{\hat{e}}^{c}$ & 5,0907 & $0,0000^{* * * *}$ & 5,0000 & $0,0000^{* * * *}$ \\
\hline$P_{\hat{e}}^{c}$ & 48,5444 & $0,0001^{* * *} *$ & 48,0003 & $0,0002^{* * * *}$ \\
\hline \multicolumn{5}{|l|}{ BUY } \\
\hline$Z_{\hat{e}}^{c}$ & 2,3572 & $0,0092^{* * * *}$ & 3,6667 & $0,0001^{* * *} *$ \\
\hline$P_{\hat{e}}^{c}$ & 32,1433 & $0,0211^{* *}$ & 40,0003 & $0,0021 * * *$ \\
\hline \multicolumn{5}{|l|}{ BUYFIR } \\
\hline$Z_{\hat{e}}^{c}$ & 4,0182 & $0,0000^{* * * *}$ & 5,0000 & $0,0000^{* * * *}$ \\
\hline$P_{\hat{e}}^{c}$ & 42,1092 & $0,0011^{* * * *}$ & 48,0003 & $0,0002^{* * *}$ \\
\hline \multicolumn{5}{|l|}{ YN } \\
\hline$Z_{\hat{e}}^{c}$ & - & - & - & - \\
\hline$P_{\hat{e}}^{c}$ & - & - & - & - \\
\hline \multicolumn{5}{|l|}{ DK } \\
\hline$Z_{\hat{e}}^{c}$ & - & - & - & - \\
\hline$P_{\hat{e}}^{c}$ & - & - & - & - \\
\hline \multicolumn{5}{|c|}{$\begin{array}{l}\text { Maksimum ortak faktör sayısı } 2 \text { olarak alınmıştır. Maksimum gecikme uzunluğu } 2 \text { olarak belirlenmiştir. ***, ** ve * sırasıyla } \% 1, \% 5 \text { ve } \% 10 \\
\text { anlamlılık düzeyini göstermektedir. } \\
\mathrm{H}_{0} \text { : Birim Kök vardır (seri durağan değildir) }\end{array}$} \\
\hline
\end{tabular}

PANIC birim kök testinin sıfir hipotezi "panel verideki zaman serileri birim kök içermektedir" şeklindedir. PANIC birim kök test istatistikleri incelendiğinde sıfır hipotezi reddedilmiş ve serilerin düzey değerlerinde durağan oldukları bir başka deyişle birim kök 
içermedikleri tespit edilmiştir. Durağanlık incelemesi sonrasında model tahmin sürecine geçilebilmektedir. Model tahmininden önce panel kantil regresyon modelinin en küçük kareler modeline göre daha robust tahminler verip veremeyeceğinin belirlenebilmesi amacıyla simetri durumu Wald testi ile araştırılmıştır. Q1=0.25 ve Q3=0.75 dilimlerinin hesaplanmasının gerekli olduğu ise sıfır hipotezi reddedilemeyerek tespit edilmiştir.

Tablo: 6

\section{Simetrik Kantil Wald Testi Sonuçları}

\begin{tabular}{|c|c|c|c|c|c|}
\hline \multirow{5}{*}{ ROA } & \multicolumn{2}{|l|}{ Test Özeti } & ki-kare istatistik & ki-kare d.f. & Olasılık Değeri \\
\hline & \multicolumn{2}{|l|}{ Wald Testi } & 86,57132 & 6 & 0,0000 \\
\hline & \multicolumn{5}{|c|}{ Sınırlama Detayı: $b(\operatorname{tau})+b(1-\operatorname{tau})-2 * b(.5)=0$} \\
\hline & Kantil & Değişken & Sinırlama Değeri & Std. Hata & Olasılık Değeri \\
\hline & 0,$25 ; 0,75$ & $\mathrm{C}$ & 0,219448 & 0,036426 & 0,0000 \\
\hline \multirow{5}{*}{ TOBIN'S Q } & \multicolumn{2}{|l|}{ Test Özeti } & ki-kare istatistik & ki-kare d.f. & Olasılık Değeri \\
\hline & \multirow{2}{*}{\multicolumn{5}{|c|}{$\begin{array}{ll}\text { Wald Test } & \\
\text { Sinırlama Detayı: } b(\operatorname{tau})+b(1-\operatorname{tau})-2 * b(.5)=0\end{array}$}} \\
\hline & & & & & \\
\hline & Kantil & Değişken & Sinırlama Değeri & Std. Hata & Olasılık Değeri \\
\hline & 0,$25 ; 0,75$ & $\mathrm{C}$ & 1,456811 & 0,389175 & 0,0002 \\
\hline
\end{tabular}

Wald testi için oluşturulmuş sıfır hipotezi "simetri vardır" şeklindedir. Her iki model için gerçekleştirilen Wald testi sonuçlarına göre panel kantil regresyonun panel EKK yöntemine göre daha etkin sonuçlar verdiği de tespit edilmiştir. Her üç kantil dilimi için modeller tahminlenmiş ve hataların mutlak sapmasının en küçük olduğu Q2 $=0.5$ dilimi için model değerlendirmesi ve yorumlamalar yapılmıştır. Panel kantil regresyon modelinin tahmininde verilerin panel veri oluşu ve zaman boyutu dikkate alınarak Bootstrap yöntemi doğrultusunda 500 iterasyon ve 100 replikasyon ile Knuth (1969) algoritması ile rastsal üretim (random generator) kullanılarak tahmin sonuçları Tablo 7'de gösterilmektedir.

ROA ve TOBINQ modelleri için oluşturulan Panel kantil regresyon modellerinin uyum iyiliği ölçütü olan Quasi LR test olasılık değerleri< $<0.05$ olduğu için modellerin anlamlı ve geçerli olduğu belirlenmiştir. ROA modelinin Pseudo $\mathrm{R}^{2}$ değeri $\% 13,2$ olarak hesaplanırken, TOBINQ modeli için ise Pseudo $\mathrm{R}^{2}$ değeri \%22,14 olarak hesaplanmıştır. Bu bağlamda bağımsız değişkenlerin ROA bağımlı değişkendeki değişimlerin ilgili dönemde \%13,2'sini açıkladığı ve etkilediği tespit edilirken, TOBINQ değişkenindeki değişimlerin ise \%22,14'ünü açıkladığ1 ve etkilediği tespit edilmiştir. ROA model sonuçları incelendiğinde, finansal esnekliğin ölçütü olan yüksek nakit ve düşük kaldıracı temsil eden YN ve DK değişkenlerinin olasılık değerlerinin anlamlı ve katsayılarının pozitif olduğu belirlenmiştir. Dolayısıyla, inşaat sektöründe faaliyet gösteren firmalar için finansal esnekliğin geçerli olduğu ve finansal performansı pozitif yönde etkilediği ortaya çıkarılmıştır. Bağımsız değişken konumunda olan kontrol değişkenlerinden TOBINQ, BUY ve BUYFIR ile ROA arasında da anlamlı ve pozitif yönlü ilişki tespit edilmiştir. Buna göre, firmaların firma değeri, firma büyüklükleri (toplam varlıklarının logaritması) ve büyüme fırsatları (satışlar) arttıkça finansal performansın da arttığ 1 belirlenmiştir. TOBINQ değişkenindeki bir birim artış finansal performansı 0,1288 birim artırırken, büyüme fırsatındaki bir birim artış ise 0,0076 birim artırmaktadır. Diğer yandan firma büyüklüğünde $\% 1$ 'lik artış ise finansal performansta \%0,58 artışa yol açmaktadır. YN ve DK kukla değişkenlerinin ise finansal performans 10,0082 ve 0,0098 birim artırdığı da tespit edilmiştir. 


\section{Tablo: 7}

\section{Panel Bootstrap Kantil Regresyon Sonuçları}

\begin{tabular}{|c|c|c|c|c|c|}
\hline Kantil $(\tau)$ & Parametreler & Katsayılar & Standart Hata & t-istatistiği & Olasılık Değeri \\
\hline \multirow{6}{*}{$\begin{array}{c}\tau=0.25 \\
\text { ROA }\end{array}$} & YN & 0,000896 & 2,167870 & 0,0321 & 0,001943 \\
\hline & DK & 0,000752 & 2,090609 & 0,0387 & 0,001572 \\
\hline & TOBIN & 0,001192 & 3,087837 & 0,0025 & 0,003680 \\
\hline & BUY & 0,000217 & 10,44673 & 0,0000 & 0,002269 \\
\hline & BUYFIRS & 0,000378 & 0,965738 & 0,3361 & 0,000365 \\
\hline & $\mathrm{C}$ & 0,004851 & $-10,06426$ & 0,0000 & $-0,048826$ \\
\hline \multicolumn{6}{|c|}{ Olasılık (Quasi-LR istatistik) = 0,749994 - R2=0,016018 } \\
\hline Kantil $(\tau)$ & Parametreler & Katsayılar & Standart Hata & t-istatistiği & Olasılık Değeri \\
\hline \multirow{6}{*}{$\begin{array}{c}\tau=0.50 \\
\text { ROA }\end{array}$} & YN & 0,008229 & 0,003640 & 2,260819 & 0,0256 \\
\hline & DK & 0,009872 & 0,003513 & 2,809893 & 0,0058 \\
\hline & TOBIN & 0,012883 & 0,005480 & 2,350939 & 0,0204 \\
\hline & BUY & 0,005848 & 0,000842 & 6,944432 & 0,0000 \\
\hline & BUYFIRS & 0,007635 & 0,001547 & 4,935695 & 0,0000 \\
\hline & $\mathrm{C}$ & $-0,133317$ & $\begin{array}{r}0,019662 \\
\end{array}$ & $-6,780341$ & 0,0000 \\
\hline \multicolumn{6}{|c|}{ Olasılık (Quasi-LR istatistik) $=0,0000-$ R2=0,132067 } \\
\hline Kantil $(\tau)$ & Parametreler & Katsayılar & Standart Hata & t-istatistiği & Olasılık Değeri \\
\hline \multirow{6}{*}{$\begin{array}{c}\tau=0.75 \\
\text { ROA }\end{array}$} & YN & 0,031292 & 0,006051 & 5,171606 & 0,0000 \\
\hline & DK & 0,014941 & 0,006658 & 2,244175 & 0,0267 \\
\hline & TOBIN & 0,013802 & 0,011231 & 1,228902 & 0,2215 \\
\hline & BUY & $-0,001040$ & 0,001841 & $-0,565180$ & 0,5730 \\
\hline & BUYFIRS & 0,021222 & 0,003246 & 6,537554 & 0,0000 \\
\hline & $\mathrm{C}$ & 0,001639 & 0,042829 & 0,038262 & 0,9695 \\
\hline \multicolumn{6}{|c|}{ Olasılık (Quasi-LR istatistik) $=0,0000-\mathrm{R2}=\mathbf{0 , 1 9 8 8 2 9}$} \\
\hline Kantil $(\tau)$ & Parametreler & Katsayılar & Standart Hata & t-istatistiği & Olasılık Değeri \\
\hline \multirow{6}{*}{$\begin{array}{c}\tau=0.25 \\
\text { TOBIN'S Q }\end{array}$} & YN & 0,149269 & 0,035993 & 4,147191 & 0,000100 \\
\hline & DK & 0,190111 & 0,035375 & 5,374103 & 0,000000 \\
\hline & ROA & 0,375045 & 0,379224 & 0,988980 & 0,324700 \\
\hline & BUY & $-0,057882$ & 0,009292 & $-6,229509$ & 0,000000 \\
\hline & BUYFIRS & $-0,004391$ & 0,019357 & $-0,226815$ & 0,821000 \\
\hline & $\mathrm{C}$ & 1,884667 & \begin{tabular}{|c|}
0,184651 \\
\end{tabular} & 10,206620 & 0,000000 \\
\hline \multicolumn{6}{|c|}{ Olasılık (Quasi-LR istatistik) $=\mathbf{0 , 0 0 0 0}-\mathbf{R 2}=\mathbf{0 , 1 6 6 0 0 4}$} \\
\hline Kantil $(\tau)$ & Parametreler & Katsayılar & Standart Hata & t-istatistiği & Olasılık Değeri \\
\hline \multirow{6}{*}{$\begin{array}{c}\tau=0.50 \\
\text { TOBIN'S Q }\end{array}$} & YN & 0,161141 & 0,051761 & 3,113163 & 0,0023 \\
\hline & DK & 0,270655 & 0,053177 & 5,089702 & 0,0000 \\
\hline & ROA & 1,841409 & 0,465819 & 3,953053 & 0,0001 \\
\hline & BUY & $-0,048748$ & 0,013006 & $-3,748134$ & 0,0003 \\
\hline & BUYFIRS & $-0,004677$ & 0,025199 & $-0,185602$ & 0,8531 \\
\hline & $\mathrm{C}$ & 1,760787 & 0,257317 & 6,842883 & 0,0000 \\
\hline \multicolumn{6}{|c|}{ Olasılık (Quasi-LR istatistik) $=0,0000-\mathrm{R} 2=0,221406$} \\
\hline Kantil $(\tau)$ & Parametreler & Katsayılar & Standart Hata & t-istatistiği & Olasılık Değeri \\
\hline \multirow{6}{*}{$\begin{array}{c}\tau=0.75 \\
\text { TOBIN'S Q }\end{array}$} & YN & 0,099631 & 0,051305 & 1,941940 & 0,0545 \\
\hline & DK & 0,510593 & 0,065262 & 7,823771 & 0,0000 \\
\hline & ROA & 0,930635 & 0,605177 & 1,537789 & 0,1267 \\
\hline & BUY & $-0,101899$ & 0,018271 & $-5,577017$ & 0,0000 \\
\hline & BUYFIRS & $-0,052277$ & 0,023190 & $-2,254311$ & 0,0260 \\
\hline & $\mathrm{C}$ & 3,093718 & \begin{tabular}{|r|}
0,371639 \\
\end{tabular} & 8,324531 & 0,0000 \\
\hline \multicolumn{6}{|c|}{ Olasılık (Quasi-LR istatistik) $=0,0000-$ R2 $=0,298060$} \\
\hline
\end{tabular}

TOBINQ için oluşturulan diğer modelde ise yüksek nakit ve düşük kaldıraç değişkenleri ile firma değeri arasında anlamlı ve pozitif yönlü ilişkinin varlığı ortaya çıkarılmıştır. Bu bağlamda inşaat sektöründe faaliyet gösteren firmalarda finansal esnekliğin geçerli olduğu ve firma değerini de pozitif etkilediği belirlenmiştir. Yüksek nakit değişkenindeki bir birim artış firma değerinde 0,1611 birim artışa yol açarken, düşük kaldıraçtaki bir birim artış ise firma değerinde 0,2706 birim artışa yol açmaktadır. ROA değiş̧kenindeki bir birim artış ise firma değerini 1,8414 birim artırırken, firma büyüklüğündeki \%1'lik artış ise firma değerinde \%4,87 azalışa yol açmaktadır. Buna karşıın büyüme firsatı ile firma değeri arasında ise istatistiksel olarak anlamlı herhangi bir ilişki tespit edilememiştir. 
Bir firmanın finansal esnekliğe sahip olabilmesi için finansal kaldıraç oranın düşük, nakit düzeyinin yüksek olması ve bu iki faktörün firmaya etkisinin pozitif olması beklenmektedir. Araştırmanın temel hipotezleri, finansal esnekliğe sahip olan firmaların finansal performanslarının ve firma değerlerinin daha yüksek olacağı diğer bir deyişle finansal esneklik ile finansal performans ve firma değeri arasında pozitif ilişkinin olmasıdır. ROA ve TOBINQ değişkenleri için oluşturulan her iki modelde de araştırmanın temel hipotezi kabul edilmiştir.

\section{Sonuç ve Değerlendirme}

Türkiye'nin en önemli sektörlerden biri olan inşaat sektöründe özellikle küresel finansal kriz sonrasında finansal derinliğin sağlanabilmesi için yeni düzenlemeler gerçekleştirilmiştir. İnşaat firmalarının duran varlık yatırımları doğrultusunda finansman politikası ve nakit yönetiminde optimal yaklaşımı sergilemeleri gerekmektedir. Bu firmalarda temel amaç maliyetleri minimize ederek nakit varlıklarını optimize etmek ve daha yüksek kar elde etmektir. Firmaların finansal kaldıraçtan düşük düzeyde yararlanmaları ve yüksek nakit mevcuduna sahip olmaları firmaların finansal esnekliğini artırmaktadır. Finansal esnekliğe sahip olan firmalar, daha düşük maliyetle fon bulabilmekte ve yeniden yapılandırma yeteneğine sahip olabilmektedir. Dolayısıyla, finansal esnekliğe sahip firmaların finansal performansları ve firma değerleri daha yüksek gerçekleşebilmektedir.

İnşaat sektöründe faaliyet gösteren firmaların 2013:12-2020:06 döneminde finansal esneklikleri ile finansal performans ve firma değerleri arasındaki ilişki panel kantil regresyon yöntemi ile analiz edilmiştir. Panel kantil regresyon analizi kapsamında, değişkenler arasında çoklu doğrusal bağlantı ve içsellik, yatay kesit bağımlılığı, durağanlık ve simetri varsayımları sınanarak panel kantil regresyon sonuçları elde edilmiştir. Analiz sonuçlarına göre finansal esnekliği ifade eden düşük kaldıraç ve yüksek nakit değişkenleri ile finansal performans göstergesi olan aktif kârlılık oranı ve firma değeri göstergesi olan Tobin's Q oranı arasında anlamlı ve pozitif ilişki tespit edilmiştir. Bu bağlamda inşaat sektöründe faaliyet gösteren firmaların incelenen dönem itibariyle finansal esnekliğe sahip oldukları ve finansal esnekliğin finansal performansı ve firma değerini artırdığı sonucuna ulaşılmıştır. Bu sonuçlar doğrultusunda araştırma kapsamında oluşturulan " $\mathrm{H}_{1}$ : Finansal esneklik ile finansal performans arasında pozitif ilişki vardır" ve " $\mathrm{H}_{2}$ : Finansal esneklik ile firma değeri arasında pozitif ilişki vardır" reddedilememiştir. Çalışmada elde edilen bu bulgular Arslan vd. (2008), Gamba ve Triantis (2008), Marchica ve Mura (2010), Mokhtar, Salamudin ve Zambahari (2013), Liping, Zhe ve Shu (2013), Ayaydın vd. (2014), Abdioğlu ve Aytekin (2016) ve Chang ve Ma (2019) tarafından yapılan çalışmalarda ulaşılan bulguları destekler niteliktedir.

İnşaat firmalarının finansal esnekliğe sahip oldukları ve bu durumun finansal performanslarına ve firma değerlerine olumlu katkı yaptığı söylenebilmektedir. Finansal esnekliğe sahip olan bu firmaların olası kriz dönemlerinde ve piyasaların etkin olmadığı koşullarda düşük maliyetli fon sağlama, finansal yükümlülüklerini karşılayabilme ve finansal piyasalara kolayca girebilme yeteneğine diğer bir deyişle kapasitesine sahip 
olduklarını söylemek mümkündür. Ayrıca bu firmaların fon bulmada zorluk yaşamadıkları ve kârlı yatırım fırsatlarını kolaylıkla finanse edebilecekleri de söylenebilir. Dolayısıyla, finansal performanslarını ve firma değerlerini artırmak isteyen firmaların finansal esneklikleri doğrultusunda finansman ve yatırım politikalarını oluşturmaları önem arz etmektedir. Diğger bir deyişle bu firmalar yüksek nakit bulundurarak ve finansal kaldıraçtan yararlanma düzeylerini düşürerek oluşturdukları politikalar doğrultusunda daha başarılı olabilmekte, finansal sıkıntı ve iflas maliyetleri ile karşı karşıya kalmamakta ve piyasadaki varlıklarını daha sağlıklı bir şekilde sürdürebilmektedir. İnşaat sektörüne yatırım yapmayı düşünen yatırımcıların da inşaat firmalarının mali tablolarını analiz ederek firmaların nakit mevcudu ve borçlanma düzeyleri doğrultusunda finansal esnekliklerini incelemeleri açısından çalışmada ulaşılan bulgular önem arz etmektedir. Türkiye'de finansal esnekliğe ilişkin az sayıda çalışma olması doğrultusunda bu çalışma, farklı dönemler ve sektör ya da endeksler esas alınarak sonraki çalışmalar ile geliştirilebileceği düşünülmektedir.

\section{Kaynaklar}

Abdioğlu, N. \& S. Aytekin (2016), "Finansal Esnekliğin Firma Performansı Üzerindeki Etkilerinin Değerlendirilmesi: Borsa İstanbul İmalat Sanayi Sektörü Üzerinde Bir Uygulama", Adıyaman Üniversitesi Sosyal Bilimler Enstitüsü Dergisi, 8(22), 309-327.

Altaf, N. (2020), "Working Capital Financing, Firm Performance and Financial Flexibility: Evidence from Indian Hospitality Firms", Global Business Review, <https://journals.sagepub.com/doi/full/10.1177/0972150920961371>, 22.11.2020.

Altın-Yavuz, A. \& E. Gündoğan-Aşık (2017), "Kantil Regresyon”, International Journal of Research and Development, 9(2), 137-146.

Ayaydın-Arslan, Ö. \& C. Florackis \& A. Ozkan (2008), "How and Why Do Firms Establish Financial Flexibility", Working Paper, Hull University Business School.

Ayaydın-Arslan, Ö. \& C. Florackis \& A. Ozkan (2014), "Financial Flexibility, Corporate Investment and Peformance: Evidence from Financial Crises", Review of Quantitative Finance and Accounting, 42(2), 211-250.

Bai, J. \& S. Ng (2004), “A PANIC Attack on Unit Roots and Cointegration”, Econometrica, 72(4), 1127-1177.

Breusch, T. \& A. Pagan (1980), "The Lagrange Multiplier Test and Its Applications to Model Specification in Econometrics”, Review of Economic Studies, 47(1), 239-253.

Byoun, S. (2011), Financial Flexibility and Capital Structure Decision, $<$ http://papers.ssrn.com/sol3/papers.cfm?abstract_id=1108850>, 22.11.2020.

Chang, H. \& C. Ma (2019), "Financial Flexibility, Managerial Effeciency and Firm Life Cycle on Firm Performance", Journal of Advances in Management Research, 16, 168-180.

Chen, N. \& E.N. Hsiao (2014), "Insider Ownership and Financial Flexibility”, Applied Economics, 46(29), 3609-3629.

Choi, J.J. \& M. Ju \& M. Kotabe \& L. Trigeorgis \& X.T. Zhang (2015), "Flexibility as Firm Value Driver: Evidence from Offshore Outsourcing”, Global Strategy Journal, 8(2), 351-376.

DeAngelo, H. \& A.S. Goncalves \& R.M. Stulz (2018), “Corporate Deleveraging and Financial Flexibility”, Review of Financial Studies, 31(8), 3122-3174. 
Gamba, A. \& A. Triantis (2008), “The Value of Financial Flexibility”, The Journal of Finance, 63(5), 2263-2296.

Gu, Y. \& F. Yuan (2020), "Internal Control, Financial Flexibility and Corporate Performance Based on Empirical Analysis of Listed Companies in Information Technology Industry", ISEITCE 2020 IOP Publishing Journal of Physics: Conference Series 1607 (2020), 012118.

Knuth, D.E. (1969), "Seminumerical Algorithms", The Art of Computer Programming, 2(1), Boston: Addison Wesley.

Koenker, R. \& G. Jr. Bassett (1978), "Regression Quantiles”, Econometrica, 46(1), 33-50.

Lie, E. (2005), "Financial Flexibility, Performance, and the Corporate Payout Choice", The Journal of Business, 78(6), 1-24.

Liping, X. \& L. Zhe \& L. Shu (2013), "Financial Flexibility, Corporate Investment and Performance: Evidence from China's Listed Companies", 2013 Fourth International Conference on Intelligent Systems Design and Engineering Applications, 6-7 November, China.

Ma, C. \& Y. Jin (2016), "What Drives the Relationship between Financial Flexibility and Firm Performance: Investment Scale or Investment Efficiency? Evidence from China", Emerging Markets Finance and Trade, 52(9), 2043-2055.

Marchica, M.T. (2010), "Financial Flexibility, Investment Ability, and Firm Value: Evidence from Firms with Spare Debt Capacity", Financial Management, 39(4) 1339-1365.

Meier, I. \& Y. Bozec \& C. Laurin (2016), "Financial Flexibility and the Performance During the Recent Financial Crisis", International Journal of Commerce and Management, 23(2), 79-96.

Mokhtar, I. \& N. Salamudin \& S.R. Zambahari (2013), "Financial Flexibility and Corporate Performance of Bumiputera Public Listed Companies", International Conference on Economics and Business Research, 15-16 July, Malaysia.

Özel, A.H. \& F. Sezgin (2012), “Ticari Serbestleşme-Ekonomik Büyüme İlişkisinin Bootstrap Kantil Regresyon Yardımıyla Analizi”, İktisat Fakültesi Mecmuası, 62(2), 283-303.

Pesaran, H. (2004), "General Diagnostic Tests for Cross Section Dependence in Panels", Cambridge Working Papers in Economics, Working Paper, 435.

Rapp, M.S. \& T. Schmid \& D. Urban (2014), "The value of Financial Flexibility and Corporate Financial Policy”, Journal of Corporate Finance, 29, 288-302.

Waghmare, P. \& C. Jacksone \& J. Poulose \& P. Krishnan \& S. Mundeja \& V. Deep \& V. Singh (2011), "An Empirical Study of Factors that Influence Financial Flexibility", Financial Structure and Financial Performance of a Firm, <https://scholar.google.com/scholar?hl=tr\&as_sdt=0\%2C5\&q=An+Empirical+Study+of + factors+that+influence+Financial+Flexibility $\% 2 \mathrm{C}+$ Financial+Structure+and+Financial + Performance+of $+\mathrm{a}+$ Firm\&btnG $=>$, 23.11.2020. 
Topaloğlu, E.E. \& İ. Ege (2021), "Finansal Esneklik, Firma Değeri ve Finansal Performans İlişkisi: İnşaat Sektörü Üzerine Panel Kantil Regresyon Yaklaşımı”, Sosyoekonomi, 29(49), 409-425. 